\title{
Single Glucose Biofuel Cells Implanted in Rats Power Electronic Devices
}

SUBJECT AREAS: IMMOBILIZED ENZYMES

FUEL CELLS

BIONANOELECTRONICS

ELECTROCATALYSIS

Received

21 December 2012

Accepted

25 February 2013

Published

22 March 2013

Correspondence and requests for materials should be addressed to S.C. (Serge.Cosnier@ ujf-grenoble.fr) or P.C.

(Philippe.Cinquin@ imag.fr)

\author{
A. Zebda' ${ }^{1,2}$, S. Cosnier', J.-P. Alcaraz ${ }^{2}$, M. Holzinger' ', A. Le Goff' ', C. Gondran' ', F. Boucher ' , F. Giroud', \\ K. Gorgy' ${ }^{1}$ H. Lamraoui ${ }^{3}$ \& P. Cinquin ${ }^{2}$
}

'Univ Grenoble 1, CNRS, Département de Chimie Moleculaire, UMR-5250, ICMG FR-2607, BP-53, 38041 Grenoble Cedex 9 , France, ${ }^{2}$ UJF-Grenoble 1/CNRS/TIMC-IMAG UMR 5525, Grenoble, F-38041, France, ${ }^{3}$ UroMems - 46 av. Félix Viallet - 38031 GRENOBLE cedex, France.

We describe the first implanted glucose biofuel cell (GBFC) that is capable of generating sufficient power from a mammal's body fluids to act as the sole power source for electronic devices. This GBFC is based on carbon nanotube/enzyme electrodes, which utilize glucose oxidase for glucose oxidation and laccase for dioxygen reduction. The GBFC, implanted in the abdominal cavity of a rat, produces an average open-circuit voltage of $0.57 \mathrm{~V}$. This implanted GBFC delivered a power output of $38.7 \mu \mathrm{W}$, which corresponded to a power density of $193.5 \mu \mathrm{W} \mathrm{cm} \mathrm{cm}^{-2}$ and a volumetric power of $161 \mu \mathrm{W} \mathrm{mL}$. We demonstrate that one single implanted enzymatic GBFC can power a light-emitting diode (LED), or a digital thermometer. In addition, no signs of rejection or inflammation were observed after 110 days implantation in the rat.

ince the first successful cardiac pacemaker was implanted in 1960, a variety of implantable battery-powered devices has been developed for various indications, ranging from neurological disorders to hearing loss. The development of lithium batteries in the late 1960s led to better and smaller devices, which showed multiyear longevity and high reliability ${ }^{1}$. Although such batteries continue to be considered as the first choice to power electronic medical implants, there are numerous efforts to develop alternative power-supply systems that are capable to operate independently over prolonged periods of time without the need for external recharging or refuelling ${ }^{2-4}$. Several alternatives have been explored in order to power implanted devices with energy from sources in the patient's body. However, systems that take advantage of the Seebeck thermoelectric effect, vibrations or body movements to generate power for an implanted device are limited because these techniques are dependent on the non-continuous nature of vibrations or temperature differences within the human body. GBFCs represent a more promising alternative because they are theoretically able to operate indefinitely due to the ubiquity of glucose and oxygen in the extra-cellular body fluid at constant levels of $5 \times 10^{-3} \mathrm{~mol} \mathrm{~L}^{-1}$ and 45 $\times 10^{-6} \mathrm{~mol} \mathrm{~L}^{-1}$, respectively ${ }^{5-8}$.

The production of electric power out of body fluids of animals, using glucose as fuel, was first envisioned in the 1970's. In their review, Kerzenmacher et al. mentioned implanted abiotic glucose fuel cells using noble metals as catalysts $^{3}$. However, the low specificity of the catalysts and the low power output density of these implanted devices precluded further developments.

Following recent developments in nano- and biotechnology, state-of-the-art biofuel cells guarantee high specificity to the fuel, along with satisfactory power densities. These milestones have given rise to a steady growing interest in this research field'.

Biofuel cells often employ enzymes to catalyze chemical reactions, thereby replacing traditional catalysts present in conventional fuel cells ${ }^{10-12}$. These systems generate electricity under mild conditions through the oxidation of renewable energy sources ${ }^{13}$. The advantages of biocatalysts are reactant selectivity, activity under physiological conditions, and facile manufacturability ${ }^{14}$.

With the aim of developing implantable power sources in the human body, Katz and co-workers demonstrated that a GBFC can produce electricity from a snail ${ }^{15}$ and reported more recently two "Cyborg" lobsters connected in-series to power a watch ${ }^{16}$. Rasmussen et $a l^{17}$ placed a GBFC in an insect (Blaberus discoidalis, a cockroach species). Szczupak et $a l^{18}$ implanted GBFCs in clams and connected three of them in series. With this setup, a capacitor could be charged, allowing an electrical motor to rotate. Although these experiments were not performed with mammals, these studies demonstrate that GBFCs can produce electricity out of living organisms. It 
appears that an attractive mode of operation for biofuel cells consists in the energy accumulation through capacitors for the intermittent activation of model devices. This mode of GBFC function may be applied to the activation of some sensor devices for medical monitoring.

Concerning the human implantable application, we recently reported a GBFC that is able to generate electric power inside a rat from glucose and oxygen contained in its body fluids ${ }^{19}$. This work was the first demonstration of an implanted GBFC delivering electrical power inside a living organism and, in particular, inside a mammal. However, both, the open-circuit voltage and power density were far below the levels required to supply implanted biomedical devices.

Our recent improvements in GBFC concepts in terms of carbon nanotube compression and direct electron transfer led to high opencircuit voltage (OCV), high power output, and stabilities over weeks ${ }^{20}$. Taking advantage of this improved performance, we report here an original design of a GBFC, based on carbon nanotube-matrix bioelectrodes, and its successful implantation in a rat. One single implanted GBFC device of $0.24 \mathrm{~mL}$ volume $(2.4 \mathrm{~mL}$ for the whole implant) produced the power required to operate, using a specially designed electronic circuit to charge a capacitor, two types of electronic devices: a LED and a digital thermometer.

\section{Results}

The bioelectrodes were formed by compression of a CNT/enzyme mixture to pellets and wired using a carbon paste ${ }^{20}$. Such electrodes were wrapped in a dialysis membrane and placed in a perforated silicone tube (Figure 1A), protected by a silicon layer (Figure 1B), packed in dialysis bag, and sutured inside a Dacron ${ }^{\circledR}$ sleeve (Figure 1C). The GBFC was surgically implanted in the abdominal cavity of a rat where the wires were tunnelled up to the head. These wires were then soldered to a female connector and fixed on the skull (Figure 1D and E). Details about the GBFC production and implantation can be found in the methods section.

The performance of four biofuel cells implanted in four different rats was characterized electrochemically. Figure $2 \mathrm{~A}$ shows the evolution of the OCV values of four implanted biofuel cells. The measured maximum OCVs, obtained after 6-8 days, were in the range $510-660 \mathrm{mV}$ (Figure $2 \mathrm{~B}$ ) and reflect the difference between the redox potential of laccase at the biocathode and the redox potential of GOx at the bioanode. Figure $2 \mathrm{C}$ represents the variation of the current as function of the biofuel cell voltage. For applied current between 150 and $700 \mu \mathrm{A} \mathrm{cm}{ }^{-2}$ the average voltage measured after $300 \mathrm{~s}$ of chronopotentiometry varies from $535 \mathrm{mV}$ to $220 \mathrm{mV}$. Moreover, these GBFCs can continuously deliver electricity over 10 minutes at an applied discharge current of $150 \mu \mathrm{A} \mathrm{cm} \mathrm{cm}^{-2}$, producing $9.3 \times 10^{-3} \mathrm{~J}$. It should be noted that the voltage decreased slowly from 0.55 to $0.48 \mathrm{~V}$, as it is displayed in the discharge curve of the implanted GBFC of rat 2 (Figure 2D).

To examine more accurately the GBFC voltage evolution, the latter was continuously recorded for an intermittent use of GBFC consisting of 5 minutes discharge at $50 \mu \mathrm{A} \mathrm{cm} \mathrm{cm}^{-2}$ followed by 7 minutes recovery at zero current. For four successive cycles, it appears that, during the discharge period, the GBFC loses less than $20 \mathrm{mV}$ of its initial voltage. Furthermore, the voltage increased when the discharge was stopped, reaching its initial value after 7 minutes (Figure 2E).

These results clearly demonstrate that the implanted GBFCs are able to recover their equilibrium state after the discharge period. The time necessary to reach the initial equilibrium state is most likely due to the consumption of glucose and oxygen at the vicinity or inside the porous bioelectrodes during the GBFC discharge. These successive on-off discharge cycles indicate that this GBFC is able to deliver $50 \mu \mathrm{A} \mathrm{cm} \mathrm{cm}^{-2}$ during a total of 25 minutes of discharge per hour without alterating its performance.

With the aim to illustrate the potential of implanted GBFC for powering real electronic devices, the implanted GBFC was connected to a boost converter (step-up converter) and applied to power a lightemitting diode (LED) that consumes $1.31 \times 10^{-3} \mathrm{~J}$ (details in the method section). Figure $3 \mathrm{~A}$ shows the illuminated LED connected to the GBFC via this boost converter. The related video (see supplementary informations) shows 5 successive flashes of the LED using this step-up. Taking into account the average time of energy

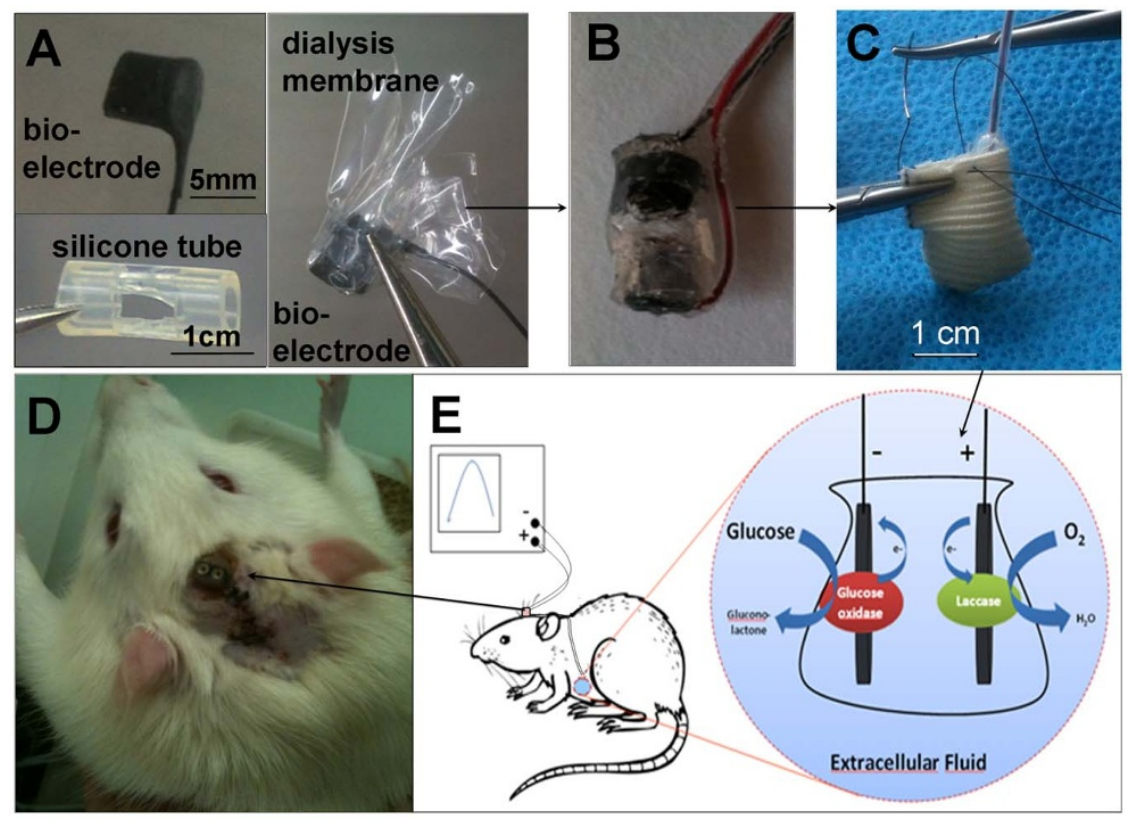

Figure $1 \mid$ From bioelectrodes to a biocompatible biofuel cell, implanted in the abdominal cavity of a rat. (A) Image of the components forming the biofuel cell: bioelectrode, perforated silicone tube, and bioelectrode wrapped in a dialysis membrane. (B) Image of our GBFC setup including both, bioanode and biocathode inserted in a silicone cylinder and sealed with silicone. (C) Photograph of the GBFC sutured in a Dacron ${ }^{\circledR}$ bag before implantation. (D) Electrical connection of the implanted GBFC in a Wistar rat; the output wires are fixed to the rat's skull. (E) Schematic description of the enzyme reactions producing electricity, their electrical connection and the GBFC location inside the rat. 
A

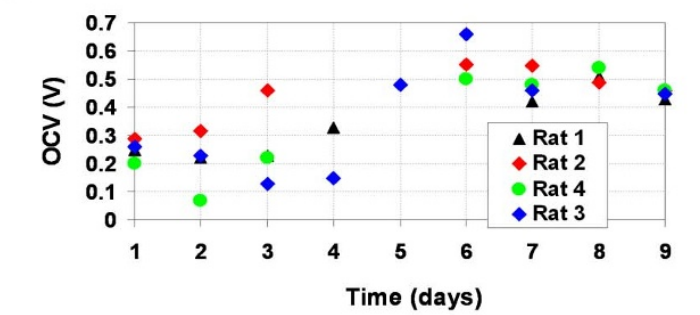

C

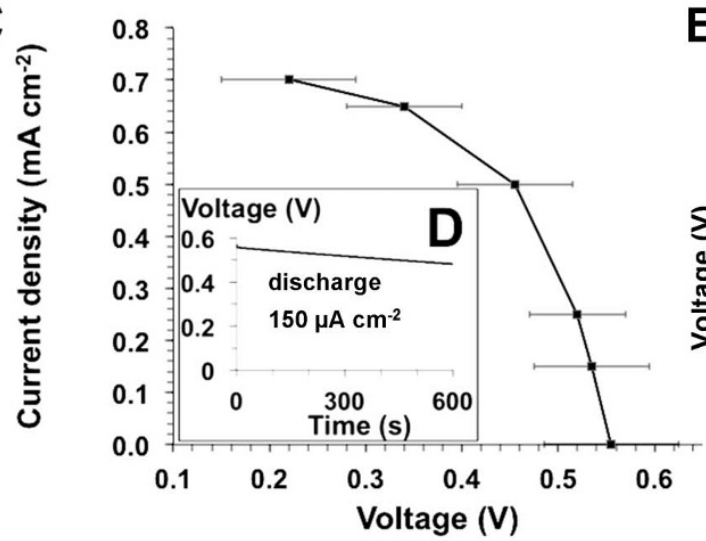

B

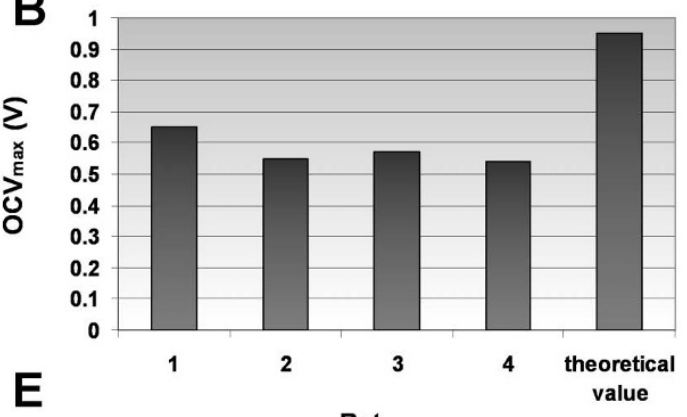

Rat

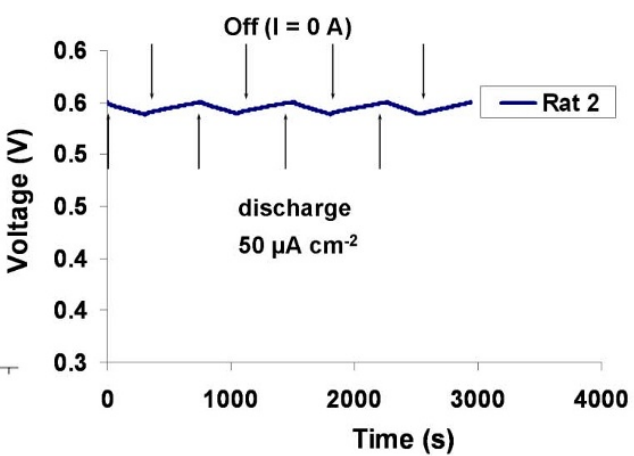

Figure 2 Electrochemical characteristics of the implanted biofuel cell. (A) Evolution of OCV over time for 4 implanted GBFCs (B) Maximum OCVs recorded after 6-8 days; (C) Current versus average voltage. Potential values measured after $300 \mathrm{~s}$ of constant current discharges in the range 150-700 $\mu \mathrm{A}$ $\mathrm{cm}^{-2}$. (D) Voltage dependence over time under continuous discharge of $150 \mu \mathrm{A} \mathrm{cm}{ }^{-2}$ (E) Evolution of the GBFC voltage during 4 discharge and stabilization cycles, using each time $50 \mu \mathrm{A} \mathrm{cm}{ }^{-2}$ discharge current for 5 minutes.

accumulation for 5 flashes as well as the power efficiency of the boost converter (75\%), the implanted GBFC supplied an average power of $38.7 \mu \mathrm{W}$ or $161 \mu \mathrm{W} \mathrm{mL}^{-1}$.

In the same way, the implanted GBFC, combined with adapted electric circuitry, was used to power an electric thermometer that requires about $75 \mu \mathrm{W}$. Figure $3 \mathrm{~B}$ and $3 \mathrm{C}$ shows the digital display of the powered and non-powered electric thermometer. It appears that the temperature is measured and displayed on an LCD screen when the device is connected to the GBFC. These results clearly show that the implanted GBFC can be considered as a real power source that is able to supply power to medical electronic devices.

Autopsies performed on the rats after 10 to 17 days show that the external side of the implant starts to be covered by a thin layer of vascularized tissues (See for instance rat 4, Figure 4A). After 110 days implantation in rat 1 , the implant is surrounded by thick adherent adipose tissue richly vascularized (Figure 4B). The Dacron ${ }^{\circledR}$ bag,

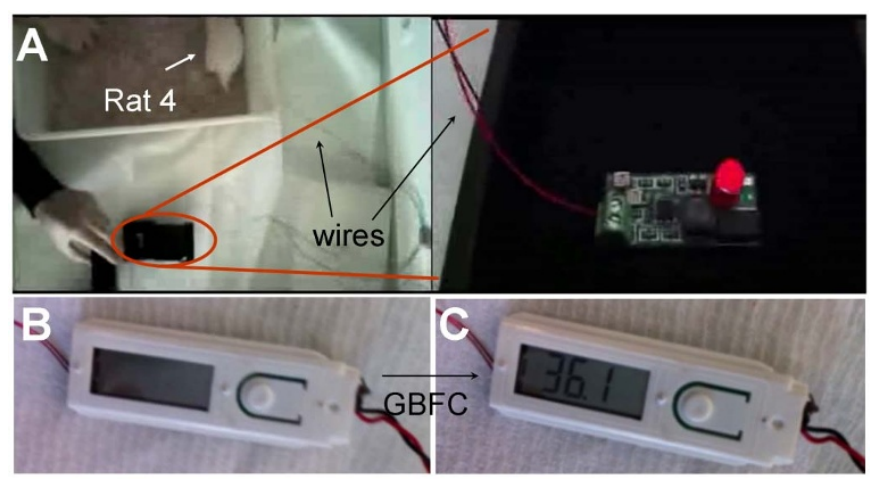

Figure $3 \mid$ A rat lights a LED and a digital thermometer (A) Image of the LED flashes after its connection to the implanted GBFC (see video in SI), Image of a digital thermometer $(\mathrm{B})$ before and $(\mathrm{C})$ after connection to the implanted GBFC. conventionally used for implants, ensures excellent biocompatibility for the GBFC. To investigate whether the implanted GBFC can modify the physical fitness of the rat or its eating habits, we monitored daily the weight of the rat and the food consumed during more than 3 months. These observations were monitored with two rats: one rat implanted with a functional GBFC (rat 1) and another with a pseudoGBFC containing BSA instead of enzymes (control rat). After a small weight loss due to the surgical intervention, the rat's weight increases gradually in a normal manner (Figure 4C) with an average food intake of $26 \pm 3 \mathrm{~g}$ per day (Figure 4D). Nevertheless, it should be noted that this behavior does not reflect the biocompatibility of the electronic device in operation for three months due to the loss of connection with the biofuel cell after 9 days.

\section{Discussion}

The single implanted GBFC that we describe produces the highest output characteristics obtained for a GBFC inside the body of a mammal. One of the principal challenges for the development of an implantable electrochemical energy converter is the biocompatibility, which we achieved by enclosing the GBFC in a Dacron ${ }^{\circledR}$ bag. Moreover, our use of porous dialysis membranes inside the Dacron ${ }^{\circledR}$ bag not only prevents the external leakage of bioelectrode components (CNTs and enzymes) from the GBFC, but also prevents inward diffusion from the body fluids of biological macromolecules which can inhibit the activity of the enzymes.

The GBFC reported here produced a greater power output compared to our first report of an implanted GBFC operating with redox mediators ${ }^{19}$. In the current GBFC, the use of direct electron transfer between enzymes and electrodes led to a 20 -fold increase in power density and an average OCV of $0.57 \mathrm{~V}$ obtained with a single GBFC. However, the in vivo performance was lower than that observed during the in vitro experiment ${ }^{20}$. This was probably due to the dioxygen concentration in extracellular fluids (which is below $4.5 \times$ $10^{-5} \mathrm{~mol} \mathrm{~L}^{-1}$ at the venous level) being about four times lower than in the air-saturated buffer solutions that were used for the in vitro 


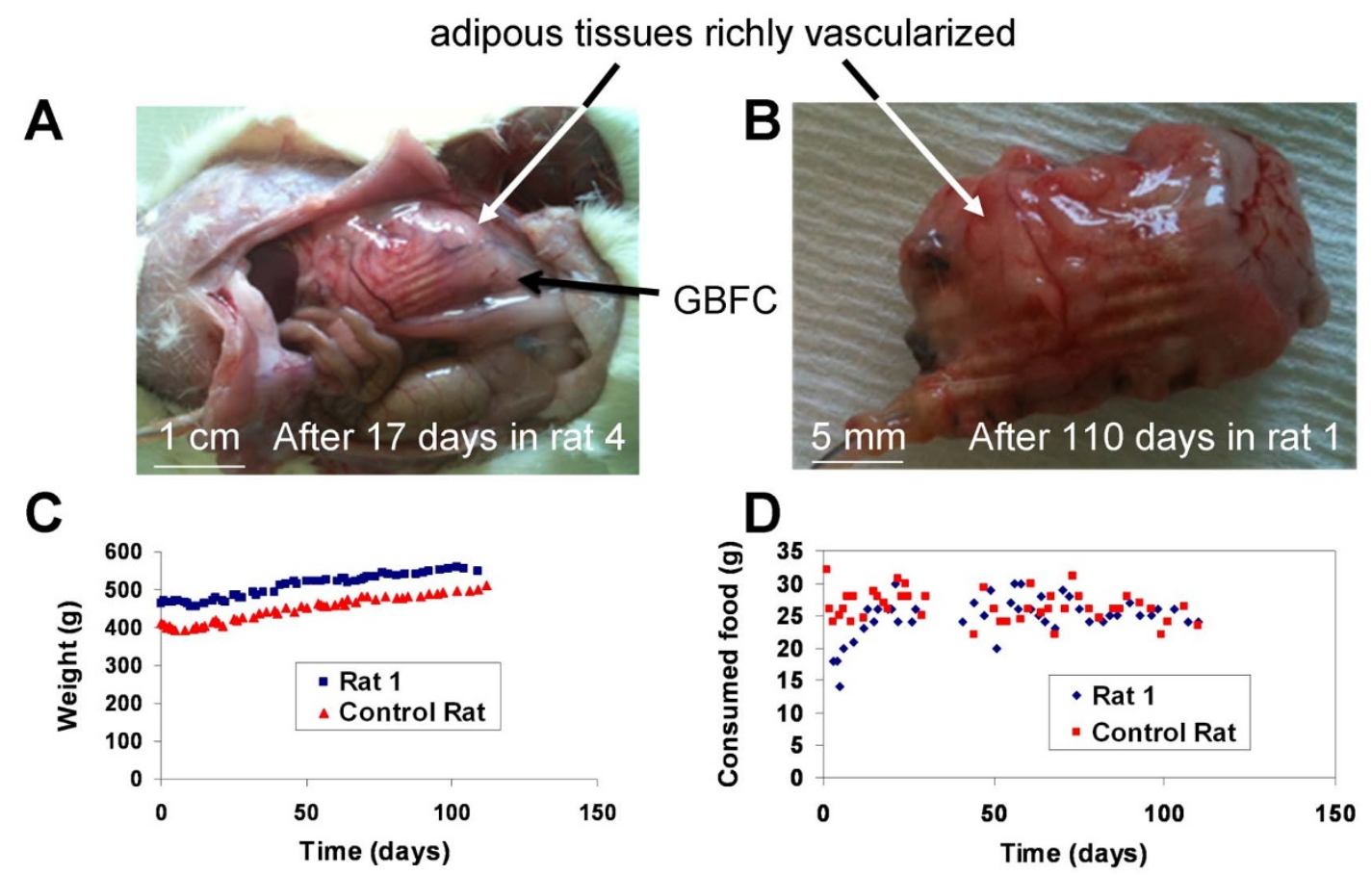

Figure $4 \mid$ Biocompatibility of the GBFC. Recovered GBFCs after (A) 17 days and (B) 110 days inside a rat. Both implants are surrounded by an adherent adipous tissue richly vascularized. Evolution of $(C)$ the weight and (D) the food intake of the rat with a GBFC (rat 1$)$ and of the control rat for 110 days.

experiments. All power consuming electrochemical tests of the implanted biofuel cells were tested 6-8 days after surgery and the maximum OCV was measured daily until the power loss of the GBFC. After autopsy of the rats and recovery of the implant, the observed power loss was in most cases due to the dislocation of the wires from the bioelectrodes and sometimes occurred because the rat dislodged the external connector used for the GBFC measurements. In order not to harm the rat, the electrical wires used to connect the cell to the external connector were very flexible and very thin. As a consequence, after about 9 days, we were faced with mechanical breakage of free wires or wire breakage and hence disconnection at the level of the bioelectrode. It is important to note that, unlike all previous experiences made by other research groups with insects, molluscs or lobsters, the animal is not immobilized or anesthetized but remains always freely moving. A clear statement about the lifetime of our biofuel cells is therefore not possible until those engineering issues are resolved.

The obtained power density of our implanted GBFC represents a promising solution to several issues for electronic medical devices. Compared to our previous results ${ }^{19}$, the volumetric power characteristics represent an 7 -fold increase in performance $\left(161 \mu \mathrm{W} \mathrm{mL} \mathrm{mL}^{-1}\right.$ vs $24.4 \mu \mathrm{W} \mathrm{mL} \mathrm{mL}^{-1}$ ) for a single implanted GBFC inside the body of a mammal, with an excellent biocompatibility ensured by the Dacron ${ }^{\circledR}$ bag. The GBFC that we report produces significant levels of energy at a single location and hence could be utilized as the power source for implanted sensor devices dedicated to medical monitoring. Further optimization of our GBFC could be expected to provide opportunities for other medical applications such as Multiple-lead Cardiac Resynchronisation Therapy (promising for some types of Heart Failures), or peripheral nerve stimulations (e.g. for pain control). In the case of peripheral nerve stimulation several small GBFCs could be used instead of the currently implanted bundle of wires from a single sealed battery.

\section{Methods}

Ethics statements. The care of the rats was approved by the European Communities Council Directive Animal Care and Use Committee. The experiments were performed in accordance to their guiding principles (European Communities Council Directive L358-86/609/EEC). All protocols involving living animals were performed under license from the French Ministry of Agriculture (License number 38018 and 381141). The Committee on the Ethics of Animal Experiments of the Grenoble University (ComEth) approved the protocol under the number 103_LERPRETA-JPA-01).

Chemicals. Commercial thin Multi-walled Carbon Nanotubes (9.5 nm diameter, purity $>95 \%$ ) obtained from Nanocyl were used as received without any purification step. Glucose oxidase (GOx) from Aspergillus niger (100 $\mathrm{U} \mathrm{mg}^{-1}$ solid), laccase from Trametes versicolor ( $20 \mathrm{U} \mathrm{mg}^{-1}$ solid) were purchased from Sigma-Aldrich and used without further purification. Cellulose membranes were purchased from Spectrumlabs: Spectra/Por ${ }^{\circledR}$ Dialysis membrane, MWCO 6-8000 $\mathrm{g} \mathrm{mol}^{-1}$, flat width $32 \mathrm{~mm}$, diameter $20.4 \mathrm{~mm}$, vol/length $3.3 \mathrm{~mL} / \mathrm{cm}$.

Instrumentation. The electrochemical characterization and the biofuel cell tests were performed with an Autolab potentiostat 100 (Eco Chemie, Utrecht, The Netherlands).

Procedures to fabricate the bioelectrodes and the GBFC. The enzymes are mechanically confined into a CNT matrix by compression of a CNT/enzyme mixture as reported ${ }^{20}$, affording direct electrical wiring between the redox active center and the electrode. Furthermore, the CNT matrix ensures high conductivity and high porosity, necessary for the diffusion of substrates. The bioelectrodes used for implantation are pellets with $6 \mathrm{~mm}$ thickness and $5 \mathrm{~mm}$ in diameter. Although only laccase is used at the cathode, GOx is combined with catalase at the anode. Catalase catalyzes the decomposition of hydrogen peroxide, produced by unwired GOx and hence prevents enzyme deactivation and serves for local oxygen depletion ${ }^{21}$. The whole GBFC was then formed by connecting the bioanode and biocathode.

Miniaturized insulated wires (UBA3219, industrifil) are connected to the CNT pellets via a conductive ink (Electrodag 423SS) (see manuscript: Fig. 1A bottom). Each pellet was then wrapped in a cellulose acetate membrane (see manuscript: Fig. 1A middle). These electrodes were then inserted into a perforated silicone sleeve (inner diameter: $5 \mathrm{~mm}$ ) (see manuscript: Fig. 1A top) and enclosed by a silicone ring. Before use, the dialysis membrane, solutions and catheters were sterilized using an autoclave. The wires were then introduced into a biocompatible silicone tubing (721048, Harvard Apparatus; $1.9 \mathrm{~mm}$ outside diameter) that were then filled to a length of $3 \mathrm{~cm}$ with medical grade silicone. Silicone was also used to cover the non-biocatalytic parts of the silicone mould (see manuscript: Fig. 1.B). Thus, no wound or trauma can be imputed to the electrical circuitry and the wires were protected from short circuits.

The bagging of the implanted cell was carried out under a laminar flow hood under sterile conditions. The silicone sleeve containing the electrodes is inserted in a $16 \mathrm{~mm}$ flat width dialysis bag with a 100-500 Daltons MWCO (131054 Spectrumlabs). The bag is then filled with approximately $1 \mathrm{~mL}$ sterile Ringer solution and closed while 
avoiding air bubbles. The biocompatibility of the resulting device in the rat is due to an autoclaved Dacron ${ }^{\circledR}$ sleeve, wrapped around the dialysis bag, cut to the right volume, and then sutured with surgical filament (see manuscript: Fig. 1C)

Surgical implantation of the GBFC inside a rat. Male Wistar rats weighing $300-560 \mathrm{~g}$ were anesthetized with isoflurane under inhalational conditions. A median laparotomy was performed to insert the implant into the retroperitoneal space in left lateral position. The catheters containing the wires of the GBFC are subcutaneously tunnelled from the abdomen up to the head of the rat (see manuscript: Fig. 1D and 1E). The wires were then soldered to a female microconnector (BL3.36Z fischer electronik) which was insulated and fixed to the skull by acrylic cement ${ }^{22}$. The GBFC was implanted in the retroperitoneal space (Fig. 1E) of the rat because the composition of the extracellular fluid in terms of glucose and oxygen is the same as in blood. The muscular abdominal wall and the skin were finally sutured separately and the animals allowed to recover from anaesthesia. After surgery, the animals received a single injection of an analgesic (Rimadyl, $5 \mathrm{mg} \mathrm{kg}^{-1}$, i.m.).

After implantation, the rats were left to recover 24 hours. Each day, the rats were connected to a potentiostat to measure the open circuit voltage of the implanted GBFC.

The rats were not immediately sacrificed after the performance studies in order to evaluate the biocompatibility of the implants. As required, the rats were euthanized under anaesthesia (sodium pentobarbital $50 \mathrm{mg} \mathrm{kg}^{-1}$, i.p.) by intra-cardiac injection of sodium pentobarbital $(100 \mathrm{mg})$.

Power management of the glucose biofuel cell. Two different electronic devices have been designed to demonstrate the power management of the implanted biofuel cell. One is for powering a common medical digital thermometer (power consumption: $50 \mu \mathrm{A}$ at $1.5 \mathrm{~V})$ and another to light a LED $(4.1 \mathrm{~mA}$ at $2.9 \mathrm{~V})$. Both electronic designs are based on a low input voltage boost converter (BQ25504, Texas instruments, Dallas, Texas, USA). The global efficiency of this circuit is well-suited to these devices because it is optimized to operate within the GBFC's characteristics (input voltage: $0.3 \mathrm{~V}$ to $0.6 \mathrm{~V}$, input current: 10 to $100 \mu \mathrm{A}$, output voltage: up to $3 \mathrm{~V}$ ). For instance, the power efficiency of the voltage boost converter was around $75 \%$ for the LED demonstrator (average input voltage: $0.5 \mathrm{~V}$ for an average current of $70 \mu \mathrm{A}$ and average output voltage of $2.9 \mathrm{~V}$ for an average current of $4.1 \mathrm{~mA}$ ). The principle of the power management is the same for both demonstrators (thermometer and LED), whereby a capacitor is charged by the GBFC driving the boost voltage converter. When the capacitor voltage reaches a predetermined value, the stored power is released until the capacitor voltage decreases down to a determined value. The cycle is repeated as long as the device is charged by the biofuel cell. In the case of the demonstrator to power-on the thermometer, a capacitor value of $220 \mu \mathrm{F}$ was chosen in order to keep the temperature displayed on an LCD screen for $10 \mathrm{~s}$ after a capacitor charge cycle of one minute. Regarding the LED demonstrator, the diode flashed for about $88 \mathrm{~ms}$ after $28 \mathrm{~s}, 52 \mathrm{~s}, 81 \mathrm{~s}, 115 \mathrm{~s}$, and $169 \mathrm{~s}$.

1. Holmes, C. F. Electrochemical Power Sources and the Treatment of Human Illness. J. Electrochem. Soc. Interface 12 (3 (Fall)), 26 (2003).

2. Roundy, S. On the Effectiveness of Vibration-based Energy Harvesting. J. Intell. Mater. Syst. Struct. 16 (10), 809 (2005).

3. Kerzenmacher, S., Ducrée, J., Zengerle, R. \& von Stetten, F. Energy harvesting by implantable abiotically catalyzed glucose fuel cells. J. Power Sources 182 (1), 1 (2008).

4. Görge, G., Kirstein, M. \& Erbel, R. Microgenerators for Energy Autarkic Pacemakers and Defibrillators: Fact or Fiction? Herz 26 (1), 64 (2001).

5. Mano, N., Mao, F. \& Heller, A. A Miniature Biofuel Cell Operating in A Physiological Buffer. J. Am. Chem. Soc. 124 (44), 12962 (2002).

6. Mano, N., Mao, F. \& Heller, A. Characteristics of a Miniature Compartment-less Glucose $/ \mathrm{O}_{2}$ Biofuel Cell and Its Operation in a Living Plant. J. Am. Chem. Soc. 125 (21), 6588 (2003).

7. Chen, T. et al. A Miniature Biofuel Cell. J. Am. Chem. Soc. 123 (35), 8630 (2001).

8. Rapoport, B. I., Kedzierski, J. T. \& Sarpeshkar, R. A Glucose Fuel Cell for Implantable Brain-Machine Interfaces. PLoS ONE 7 (6), e38436 (2012).
9. Holzinger, M., Le Goff, A. \& Cosnier, S. Carbon nanotube/enzyme biofuel cells. Electrochim. Acta 82, 179 (2012).

10. Minteer, S. D., Liaw, B. Y. \& Cooney, M. J. Enzyme-based biofuel cells. Curr. Opin. Biotechnol. 18 (3), 228 (2007).

11. Atanassov, P. et al. Enzymatic Biofuel Cells. The Electrochemical Society Interface 16 (2), 28 (2007)

12. Sarma, A. K., Vatsyayan, P., Goswami, P. \& Minteer, S. D. Recent advances in material science for developing enzyme electrodes. Biosens. Bioelectron. 24 (8), 2313 (2009).

13. Barton, S. C., Gallaway, J. \& Atanassov, P. Enzymatic Biofuel Cells for Implantable and Microscale Devices. Chem. Rev. 104 (10), 4867 (2004).

14. Barton, S. C. in Handbook of Fuel Cells: Advances in Electrocatalysis, Materials, Diagnostics and Durability, Volumes 5 \& 6, edited by W. Vielstich, H. A. Gasteiger \& H. Yokokawa (John Wiley \& Sons, Weilheim, 2009), Vol. 5.

15. Halámková, L. et al. Implanted Biofuel Cell Operating in a Living Snail. J. Am. Chem. Soc. 134 (11), 5040 (2012).

16. MacVittie, K. et al. From "Cyborg" Lobsters to a Pacemaker Powered by Implantable Biofuel Cells. Energy Environ. Sci. 6 (1), 81 (2013).

17. Rasmussen, M. et al. An Implantable Biofuel Cell for a Live Insect. J. Am. Chem.Soc. 134 (3), 1458 (2012).

18. Szczupak, A. et al. Living battery - biofuel cells operating in vivo in clams. Energy Environ. Sci. 5 (10), 8891 (2012).

19. Cinquin, P. et al. A Glucose BioFuel Cell Implanted in Rats. PLoS ONE 5 (5), e10476 (2010)

20. Zebda, A. et al. Mediatorless high-power glucose biofuel cells based on compressed carbon nanotube-enzyme electrodes. Nature Communications 2, 370 (2011).

21. Plumeré, N., Henig, J. \& Campbell, W. H. Enzyme-Catalyzed $\mathrm{O}_{2}$ Removal System for Electrochemical Analysis under Ambient Air: Application in an Amperometric Nitrate Biosensor. Anal. Chem. 84 (5), 2141 (2012).

22. Deransart, C. et al. Single-unit Analysis of Substantia Nigra Pars Reticulata Neurons in Freely Behaving Rats with Genetic Absence Epilepsy. Epilepsia 44 (12), 1513 (2003).

\section{Acknowledgments}

The authors would like to thank the Laboratory of Bioclinical Radiopharmaceutics (LRB) for providing rats. The authors also thank the Interdisciplinary Energy program of CNRS PR10-1-1, the ANR Emergence-2010 EMMA-043-02, and the ANR Investissements d'avenir - Nanobiotechnologies 10-IANN-0-02 programmes for financial support. This work was supported by French state funds managed by the ANR within the Investissements d'Avenir programme (Labex CAMI) under reference ANR-11-LABX-0004. Arielle Le Pellec is greatly acknowledged for technical assistance.

\section{Author contributions}

S.C. and P.C. initiated the project, designed and supervised the experiments, they analysed the data and wrote the manuscript with A.Z., C.G. and M.H. A.L.G. and A.Z. prepared and characterized GBFC before implantation, F.G., K.G., C.G., A.Z. and J.-P.A. characterized the implanted GBFC and carried out in vivo experiments, J.-P.A. and F.B. surgically operated for GBFC implantation in rats and performed the biocompatibility experiments and H.L. designed the electronic converter associated to the GBFC.

\section{Additional information}

Supplementary information accompanies this paper at http://www.nature.com/ scientificreports

Competing financial interests: The authors declare no competing financial interests. License: This work is licensed under a Creative Commons Attribution-NonCommercial-ShareALike 3.0 Unported License. To view a copy of this license, visit http://creativecommons.org/licenses/by-nc-sa/3.0/

How to cite this article: Zebda, A. et al. Single Glucose Biofuel Cells Implanted in Rats Power Electronic Devices. Sci. Rep. 3, 1516; DOI:10.1038/srep01516 (2013). 